\title{
1 Why, oh why, are so many older adults not drinking enough fluid?
}

\section{Dehydration in long-term care.}

3 Lee Hooper

4 The National Resident Assessment Instrument (RAI) was introduced a quarter century ago, was fully operational by October 1991 and appeared to reduce the prevalence of dehydration

6 from $2 \%$ to $1 \%$ in nursing home residents ${ }^{1}$. Despite this [X et al, reported in this issue of $J A N D$ ] have found that $38 \%$ of long term care residents were dehydrated (assessed using serum osmolality), and a further 30\% had impending dehydration. These 132 long-term residents of eight long term care facilities in Nashville had a blood sample and a written order for caloric supplementation, but were not receiving hospice care, enteral or parenteral nutrition. The mean age of the 247 adults included in the study (not all had a blood sample) was 83 (SD 11) years, mean body mass index (BMI) 25 (SD 5) kg/m², and 79\% were women $^{2}$. Hydration status was measured using serum osmolality (directly measured by freezing point depression). A resident was dehydrated where their serum osmolality was $>300 \mathrm{mOsm} / \mathrm{kg}$, had impending dehydration where their serum osmolality was 295$300 \mathrm{mOsm} / \mathrm{kg}$, and they were normally hydrated below $295 \mathrm{mOsm} / \mathrm{kg}^{3,4}$.

This echoes recent research in United Kingdom (UK) residential care, the Dehydration Recognition In our Elders (DRIE) study ${ }^{5}$, which found that $20 \%$ of older residents were dehydrated, and a further $28 \%$ had impending dehydration (using the same criteria as [X et al, reported in this issue of $J A N D]^{2}$ ). The DRIE population were similar to those reported here, were living in long term care, though slightly older, heavier and more male (188 adults, mean age 86, SD 8 , years, BMI $26, \mathrm{SD} 6, \mathrm{~kg} / \mathrm{m}^{2}$, and $66 \%$ women). There appear only to be two other studies from long term care settings that have assessed serum osmolality (and so assessed hydration status accurately). Stotts found that $19 \%$ of 48 United States (US) nursing 
home residents at risk for pressure ulcers were dehydrated, and a further $44 \%$ had impending

dehydration, while Gaspar found that none of 36 US long term care residents were dehydrated ( $8 \%$ had impending dehydration $)^{6,7}$. While high rates of dehydration are not totally consistent (ranging from $8 \%$ to $68 \%$ of older adults having either impending or current dehydration), these figures suggest that dehydration is common. Rates of dehydration in older adults admitted to hospital are also variable but often high (see Table) ${ }^{8}$.

So why are so many older adults living in long term care in developed countries dehydrated?

Both recent studies ${ }^{2,5}$ examined factors associated with dehydration in long term care residents in cross-sectional analyses. [X et al, reported in this issue of JAND] $]^{2}$ suggest that risk of dehydration was associated with diabetes, mental status score based on the minimental state examination (MMSE) score and higher blood urea nitrogen (BUN). Factors assessed, but not associated with dehydration in multivariate analysis included age, sex, BMI, functional status, energy intake, drink (beverage) consistency, total water intake, snack frequency, and type of oral nutrition supplement. Factors associated with dehydration in the UK DRIE $^{5}$ cohort were diabetes, lower cognitive function (also based on MMSE score) and lower estimated glomerular filtration rate (eGFR). Being male, having more health care contacts in the past 2 months and not using potassium-sparing diuretics were associated with increased risk of dehydration in some (but not all) analytic models. Factors assessed, but not associated with dehydration in DRIE included age, needing thickened drinks, needing help drinking, a variety of current and chronic health factors, a variety of measures of urinary and fecal continence, functional status, BMI, other measures of nutritional status and medications. The consistent factors associated with dehydration in both studies are diabetes, poor renal function (though measured in different ways) and poor cognition. 
52 Why are these particular factors associated, and consistently associated across continents in

different care systems, with dehydration? To discuss this we need to start by defining dehydration - a term rather like malnutrition in that it refers to several distinct problems. Malnutrition always refers to poor nutrition, but may refer to protein-energy malnutrition, or to scurvy, or to obesity, conditions which have different causes, different symptoms and different treatments. Dehydration is similar - it always refers to a shortage of fluid in the body, but covers water-loss dehydration and salt-loss dehydration, which have different causes, different symptoms and different treatments ${ }^{9}$. [X et al, reported in this issue of $J A N D]$ reports on water-loss dehydration (also called intracellular dehydration, or simply dehydration), measured by serum osmolality, which signifies that someone is not drinking enough $^{3,9,10}$. This is distinct from salt-loss dehydration (also called extracellular dehydration, or hypovolemia) where the shortage of fluid is due to excessive losses of fluid and electrolytes (and sometimes other components also, through diarrhea, vomiting, or blood loss) and serum osmolality is not raised. Water-loss dehydration is a nutritional deficiency, the result of insufficient fluid intake, and occurs in otherwise well individuals, while salt-loss dehydration is usually the result of an illness, a medical condition.

The mechanism of water-loss dehydration is that with insufficient drinking (insufficient fluid intake) the serum components become more concentrated (which raises serum osmolality). To equalize osmolality between the intracellular and extracellular fluids water moves from cells into the extracellular fluids, diluting the serum but concentrating intracellular fluid and shrinking the cells. This is water-loss dehydration. Humans are physiologically protected against water-loss dehydration and its consequences through several elegant feedback mechanisms. Cell membrane osmoreceptors are triggered as intracellular fluids become more 
concentrated, and these trigger thirst (ensuring that we seek fluid, drink, and resolve the problem). At the same time (and in case there is no fluid to drink nearby) they cause the release of vasopressin (also called antidiuretic hormone, ADH) which increases water resorption in the renal tubules, so that the urine is concentrated and further fluid loss is limited $^{10}$.

So why do so many older adults have water-loss dehydration? It appears that as people age these basic feedback mechanisms that protect them against water-loss dehydration are weakened or lost. Thirst is no longer associated with raised serum osmolality in older adults ${ }^{5}$, 11-13. At the same time renal concentrating capacity becomes more limited ${ }^{14}$, so that urine concentration (measured by urinary color, specific gravity and osmolality) ceases to indicate hydration status in older adults ${ }^{13,15,16}$. This leaves older adults at high risk of dehydration, without the normal physiological responses.

Diabetes is likely to be associated with dehydration, because when diabetes is not well controlled, and blood glucose rises, it results in higher serum osmolality (serum glucose is a component of serum osmolality, as reflected in osmolarity equations $)^{17-19}$. It is intriguing, though, that when individuals with raised or unknown serum glucose were omitted from analyses in the DRIE study, use of diabetic medication was still associated with dehydration in multivariate analyses ${ }^{5}$, suggesting that there may also be other mechanisms involved.

The association of poor renal function (measured by BUN or eGFR) with dehydration reinforces the importance of renal function in retention of fluid when fluid intake is limited, as we would expect from the physiological mechanisms. However, the association could also 
reflect a rise in BUN resulting from limited renal function. BUN (also called serum urea) is a key component of serum osmolarity equations, and of directly measured osmolality ${ }^{17-20}$.

So maybe the links between diabetes, renal function and dehydration are obvious. But, why is poor cognitive function associated with dehydration? The relationship is consistent, and appears to be linear. As cognitive function becomes more limited, both serum osmolality and the odds of dehydration rise ${ }^{5}$. As our normal physiological responses fade, it is likely that we become more dependent on routine, habit and social interaction to ensure we drink enough to maintain hydration. Dementia and limited cognition disrupt routine, and disturb social relationships (as does aging itself, as we get older we often lose key friends, relatives and partners), so that drinking may drop off without any conscious decision to reduce drinking.

With the forgetfulness of dementia older adults lose their awareness of when they last drank, and eventually lose awareness of the need to drink. In the absence of thirst the body does not prompt drinking when drinks are forgotten. On top of these problems, dehydration can worsen cognitive function, creating a vicious $\operatorname{circle}^{21,22}$.

Almost as interesting as the factors associated with dehydration are those that were tested and found not to be associated with dehydration. Eating and drinking dependence and total functional status were assessed and found not to be strongly related to serum osmolality in multivariate analyses in either study ${ }^{2}, 5$. This suggests that in the context of long term care those who struggle to drink or gain access to drinks are appropriately supported, so that this potential risk factor is overcome $\mathrm{e}^{23}$. Needing thickened drinks was also assessed in both studies and not found related to serum osmolality, but in the case of DRIE there were few participants needing thickened drinks, so analyses may simply be underpowered, and larger studies will be needed to assess this relationship. Age was not related to serum osmolality in 
either study, perhaps because in the long term care context all are frail and most are either cognitively or functionally limited, regardless of their age - so that age may still predict dehydration (as an indicator of frailty) in older adults living independently in the community (research in those living independently will be needed to test this hypothesis). BMI was not associated with serum osmolality in either multivariate analysis.

Perhaps most intriguing, given that serum osmolality reflects inadequate fluid intake, [X et al, reported in this issue of JAND] found no relationship between total fluid intake and serum osmolality. Does this suggest that fluid needs are highly individual, or an inability to accurately measure fluid intake in older adults in this setting? The methodology of fluid assessment in this study appears very strong, weighing all food and fluid intake at meal and snack times, over two 24-hour periods. However, long term care residents in the UK often drink between set meal and snack times. Residents may keep a bottle of lemonade or a special type of fruit juice in their bedroom, drink water from a jug in their room, or directly from their faucet. Visitors may make drinks for residents, request them from care staff (to share with residents) or take residents out for drinks to local shops, cafes, bars or tea rooms. Fluids taken with medications can also be important for fluid intake. The relationship between drinks intake and hydration status needs to be explored further in future research, perhaps assessing daily water turnover very accurately using deuterium oxide ${ }^{24}$.

The crucial question, raised by [X et al, reported in this issue of JAND], is what this tells us about how we support older adults to drink well. The authors provide good suggestions for actions we can take. While many interventions have been tested, none are clearly effective at promoting fluid intake and protecting against dehydration in older adults ${ }^{25,26}$. We need methodologically rigorous and well-powered studies to assess ways to improve fluid intake in 
older adults. A variety of avenues need to be explored, remembering that in the absence of basic physiological protection against dehydration we need to ensure that older adults are aware of the need to drink, and that because they are not feeling thirsty they must not assume they have drunk enough. We may need to provide older people with tools to assess and monitor their own drinking (for example a Drinks Diary, recently developed to help older adults in residential care to record their own drinks intake $\left.{ }^{27}\right)$. Multifactorial interventions including individual assessment of barriers to drinking, education, monitoring, prompting, variety, regularity and choice of drinks, addressing continence and even medications may be needed, as well as interventions at local and national policy levels ${ }^{25}$. As care-givers, we must consider how to support continued drinking even in the face of receding cognitive function by supporting social relationships, routine and the enjoyment of drinking ${ }^{26}$.

\section{Reference List}

(1) Fries BE, Hawes C, Morris JN, Phillips CD, Mor V, Park PS. Effect of the National Resident Assessment Instrument on selected health conditions and problems. $J$ Am Geriatr Soc 1997;45(8):994-1001.

(2) xxx. Elevated Serum Osmolality and Total Water Deficit Indicate Impaired Hydration Status in Long Term Care Residents Regardless of Low or High Body Mass Index. $J$ Acad Nutr Diet 2015; accepted.

(3) Thomas DR, Cote TR, Lawhorne L et al. Understanding clinical dehydration and its treatment. JAMDA 2008;9(5):292-301.

(4) Institute of Medicine. Panel on Dietary Reference Intakes for Electrolytes and Water. Dietary Reference Intakes for Water, Potassium, Sodium, Chloride, and Sulfate. Washington DC, USA: National Academies Press; 2004.

(5) Hooper L, Bunn DK, Downing A et al. Which frail older people are dehydrated? The UK DRIE study. J Gerontol A Biol Sci Med Sci 2015;published online 9Nov2015.

(6) Stotts NA, Hopf HW, Kayser-Jones J, Chertow GM, Cooper BA, Wu H-S. Increased fluid intake does not augment capacity to lay down new collagen in nursing home residents at risk for pressure ulcers: A randomized, controlled clinical trial. Wound Repair Regen 2009;17(6):780-788. 
(7) Gaspar PM. Comparison of four standards for determining adequate water intake of nursing home residents. Res Theory Nurs Pract 2011;25(1):11-22.

(8) Morley JE. Dehydration, Hypernatremia, and Hyponatremia. Clin Geriatr Med 2015;31(3):389-399.

(9) Cheuvront SN, Kenefick RW. Dehydration: physiology, assessment, and performance effects. Compr Physiol 2014;4:257-285.

(10) Hooper L, Bunn D, Jimoh FO, Fairweather-Tait SJ. Water-loss dehydration and aging. Mechanisms of Ageing and Development 2013;136(pp 50-58):-58.

(11) Davies I, O'Neill PA, McLean KA, Catania J, Bennett D. Age-associated Alterations in Thirst and Arginine Vasopressin in Response to a Water or Sodium Load. Age Ageing 1995;24(2):151-159.

(12) Mack GW, Weseman CA, Langhans GW, Scherzer H, Gillen CM, Nadel ER. Body fluid balance in dehydrated healthy older men: Thirst and renal osmoregulation. $J$ Appl Physiol 1994;76(4):1615-1623.

(13) Hooper L, Abdelhamid A, Atreed NJ et al. Clinical symptoms, signs and tests for identification of impending and current water-loss dehydration in older people. Cochrane Database Syst Rev 2015;2015(4):CD009647.

(14) Rowe JW, Shock NW, Defronzo RA. The influence of age on the renal response to water deprivation in man. Nephron 1976;17:270-278.

(15) Fortes MB, Raymond-Barker P, Bishop C, Elghenzai S, Oliver SJ, Walsh NP. Is This Elderly Patient Dehydrated? Diagnostic Accuracy of Hydration Assessment Using Physical Signs, Urine, and Saliva Markers. J Am Med Dir Assoc 2015;16(3):221-228.

(16) Hooper L, Bunn DK, Abdelhamid A et al. Water-loss (intracellular) dehydration assessed using urinary tests, how well do they work? Diagnostic accuracy in older people. Am J Clin Nutr 2015;resubmitted Oct 2015.

(17) Hooper L, Abdelhamid A, Ali A et al. Diagnostic accuracy of calculated serum osmolarity to predict dehydration in older people: adding value to pathology lab reports. BMJ Open 2015;5:e008846.

(18) Khajuria A, Krahn J. Osmolality revisited-deriving and validating the best formula for calculated osmolality. Clin Biochem 2005;38:514-519.

(19) Heavens KR, Kenefick RW, Caruso EM, Spitz MG, Cheuvront SN. Validation of equations used to predict plasma osmolality in a healthy adult cohort. Am J Clin Nutr 2014;100(5):1252-1256.

(20) Siervo M, Bunn D, Prado C, Hooper L. Accuracy of prediction equations for serum osmolarity in frail older people with and without diabetes. Am J Clin Nutr 2014;100(3):867-876.

(21) Masento NA, Golightly M, Field DT, Butler LT, van Reekum CM. Effects of hydration status on cognitive performance and mood. Br J Nutr 2014;111:1841-1852. 
(22) Watson P, Whale A, Mears SA, Reyner LA, Maughan RJ. Mild hypohydration increases the frequency of driver errors during a prolonged, monotonous driving task. Physiol Behav 2015;147:313-318.

(23) Hooper L, Bunn DK. Should dehydration in older people be a marker of lack of quality in long term care provision? QAOA 2014;15(4):published online Nov 2014.

(24) Leiper JB, Seonaid PC, Primrose WR et al. A comparison of water turnover in older people in community and institutional settings. J Nutr Health Aging 2005;9(3):189193.

(25) Bunn D, Jimoh FO, Howard Wilsher S, Hooper L. Increasing fluid intake and reducing dehydration risk in older people living in long-term care: a systematic review. J Am Med Dir Assoc 2015;16(2):101-113.

(26) Abdelhamid A, Bunn DK, Copley M et al. Effectiveness of interventions to directly improve, maintain or facilitate food and drink intake in people with dementia: Eating and Drinking Well IN dementiA (EDWINA) systematic review and meta-analysis. BMC Geriatr 2016; accepted January 2016.

(27) Jimoh FO, Bunn D, Hooper L. Assessment of a self-reported Drinks Diary for the estimation of drinks intake by care home residents: Fluid Intake Study in the Elderly (FISE). J Nutr Health Aging 2015;19(5):491-496.

(28) Bossingham MJ, Carnell NS, Campbell WW. Water balance, hydration status, and fat-free mass hydration in younger and older adults. Am J Clin Nutr 2005;81(6):13421350.

(29) Johnson TM, Miller M, Pillion DJ, Ouslander JG. Arginine vasopressin and nocturnal polyuria in older adults with frequent nighttime voiding. J Urol 2003;170(2 Pt 1):480484.

(30) Kajii F, Sugiyama M, Gomi I. Dehydration and water intake in frail elderly at home. Bulletin of St Luke's College of Nursing 2006;32:43-50.

(31) Rodhe P. Mathematical Modelling of Clinical Applications in Fluid Therapy Karolinska Institutet; 2010.

(32) El-Sharkawy AM, Watson P, Neal KR et al. Hydration and outcome in older patients admitted to hospital (The HOOP prospective cohort study). Age Ageing 2015;44(6):943-947.

(33) Fletcher SJ, Slaymaker AE, Bodenham AR et al. Urine colour as an index of hydration in critically ill patients. Anaesthesia 1999;54(2):189-192.

(34) Kafri MW, Myint PK, Doherty D, Wilson AH, Potter JF, Hooper L. The diagnostic accuracy of multi-frequency bioelectrical impedance analysis in diagnosing dehydration after stroke. Med Sci Monit 2013;19:548-570.

(35) Walsh NP, Fortes MB, Raymond-Barker P et al. Is whole-body hydration an important consideration in dry eye? Invest Ophthalmol Vis Sci 2014;53(10):66226627. 
(36) Lindner G, Kneidinger N, Holzinger $\mathrm{U}$ et al. Tonicity balance in patients with hypernatremia acquired in the intensive care unit. Am J Kidney Dis 2009;54(4):674679.

261

262 
Table. Percentages of older people (aged 65+) with impending and current dehydration from various population samples and settings.

\begin{tabular}{|c|c|c|c|c|c|}
\hline Setting & Sample & Country & $\begin{array}{l}\text { Sample } \\
\text { size }\end{array}$ & $\begin{array}{l}\text { N (\%) with impending } \\
\text { dehydration } \\
(295-300 \mathrm{mOsm} / \mathrm{kg})\end{array}$ & $\begin{array}{l}\text { N (\%) with current } \\
\text { dehydration } \\
(>300 \mathrm{mOsm} / \mathrm{kg})\end{array}$ \\
\hline \multirow{4}{*}{$\begin{array}{l}\text { Residential } \\
\text { care }\end{array}$} & Long-term care residents & $\mathrm{US}^{2}$ & 132 & $40(30 \%)$ & $50(38 \%)$ \\
\hline & Older people living in residential care & $\mathrm{UK}^{5}$ & 188 & $52(28 \%)$ & $38(20 \%)$ \\
\hline & Long-term care or acute psychiatric unit & $\mathrm{US}^{7}$ & 36 & $3(8 \%)$ & $0(0 \%)$ \\
\hline & Nursing home residents at risk of pressure ulcers & $\mathrm{US}^{6}$ & 48 & $21(44 \%)$ & $9(19 \%)$ \\
\hline \multirow{5}{*}{$\begin{array}{l}\text { Older people } \\
\text { living at } \\
\text { home }\end{array}$} & Healthy people living in the community & $\mathrm{US}^{28}$ & 21 & $2(10 \%)$ & $2(10 \%)$ \\
\hline & $\begin{array}{l}\text { People who entered a residential research facility } \\
\text { for } 4 \text { days }\end{array}$ & $\mathrm{US}^{29}$ & 43 & $13(30 \%)$ & $2(5 \%)$ \\
\hline & Frail elderly people living at home & $\operatorname{Japan}^{30}$ & 71 & $5(7 \%)$ & $2(3 \%)$ \\
\hline & Healthy male volunteers & $\mathrm{US}^{12}$ & 10 & $2(20 \%)$ & $0(0 \%)$ \\
\hline & Healthy older people & Sweden $^{31}$ & 13 & $7(54 \%)$ & $2(15 \%)$ \\
\hline \multirow{7}{*}{$\begin{array}{l}\text { Hospitalized } \\
\text { groups }\end{array}$} & People admitted to hospital as emergencies & $\mathrm{UK}^{32}$ & 200 & NR & $69(37 \%)$ \\
\hline & $\begin{array}{l}\text { Adults (> } 60 \text { years) admitted to acute medical care } \\
\text { or emergency department }\end{array}$ & $\mathrm{UK}^{15}$ & 130 & \multicolumn{2}{|c|}{$\begin{array}{l}27(21 \%) \text { with serum osmolality } \\
\geq 295 \mathrm{mOsm} / \mathrm{kg}\end{array}$} \\
\hline & $\begin{array}{l}\text { People admitted to intensive care, surgical and } \\
\text { neurosurgical high dependency units }\end{array}$ & $\mathrm{UK}^{33}$ & 17 & $0(0 \%)$ & $4(24 \%)$ \\
\hline & $\begin{array}{l}\text { People admitted to hospital within } 48 \text { hours of a } \\
\text { mild or moderate acute stroke }\end{array}$ & $\mathrm{UK}^{34}$ & 31 & $5(16 \%)$ & $18(58 \%)$ \\
\hline & Older people admitted to an acute medical unit & $\mathrm{UK}^{35}$ & 106 & $16(15 \%)$ & $4(4 \%)$ \\
\hline & People in hospital intensive care unit (ICU) & Austria $^{36}$ & 34 & $8(24 \%)$ & $18(53 \%)$ \\
\hline & $\begin{array}{l}\text { Elderly people attending the emergency room of a } \\
\text { tertiary care center }\end{array}$ & $\begin{array}{l}\text { Sweden } \\
\left(\text { reported }^{13}\right)\end{array}$ & 40 & $14(35 \%)$ & $15(38 \%)$ \\
\hline
\end{tabular}

